\title{
Photosynthetic Light Requirements and Effects of Low Irradiance and Daylength on Phalaenopsis amabilis
}

\author{
Woei-Jiun Guo ${ }^{1}$ \\ Institute of Tropical Plant Sciences, National Cheng Kung University, 1 University Road, Tainan \\ 70101, Taiwan

\begin{abstract}
Yu-Zu Lin and Nean Lee
Department of Horticulture and Landscape Architecture, National Taiwan University, 1 Roosevelt Road Sec. 4, Taipei 10617, Taiwan
\end{abstract}

\begin{abstract}
AdDitional INDEX wORDS. orchid, crassulacean acid metabolism, CAM, PPF, photoperiod
ABstract. Phalaenopsis has become one of the most important potted plants around the world. Thus, we used a key commercial Phalaenopsis amabilis cultivar, TS97, as a model to determine the light requirements for maximal carbon fixation and photosystem II (PSII) efficiency in its leaves and to investigate the effects of low irradiance and daylength on photosynthesis and flower development. In mature 'TS97' leaves, the daily total $\mathrm{CO}_{2}$ uptake capacity and net acid fixation increased with increasing photosynthetic photon flux $(P P F)$ and saturated at $\approx 200 \mu \mathrm{mol} \cdot \mathrm{m}^{-2} \cdot \mathrm{s}^{-1}$, whereas the fluorescence ratio values were significantly reduced to 0.68 to 0.75 above $325 \mu \mathrm{mol} \cdot \mathrm{m}^{-2} \cdot \mathrm{s}^{-1} P P F$, indicating photoinhibition of PSII. Positive assimilation of the nocturnal $\mathrm{CO}_{2}$ uptake occurred at a very low PPF (less than $\left.5 \mu \mathrm{mol} \cdot \mathrm{m}^{-2} \cdot \mathrm{s}^{-1}\right)$, suggesting highly efficient use of light energy by 'TS97' plants. Leaves developed under $30 \mu \mathrm{mol} \cdot \mathrm{m}^{-2} \cdot \mathrm{s}^{-1} \mathrm{PPF}$ exhibited lower light requirement of $125 \mu \mathrm{mol} \cdot \mathrm{m}^{-2} \cdot \mathrm{s}^{-1} \mathrm{PPF}$ to reach maximal $\mathrm{CO}_{2}$ uptake, below which the daytime $\mathrm{CO}_{2}$ uptake declined dramatically. Under a 12-hour daylength, exposing the leaves to a low $P P F$ for 4 hours at any time during the day did not affect the photosynthetic capacity in 'TS97' leaves, suggesting that 8 hours of optimal irradiance is required for high-level photosynthesis, whereas the 12-hour daylength resulted in a higher $\mathrm{CO}_{2}$ uptake rate and the daily total $\mathrm{CO}_{2}$ uptake than the 8-hour daylength. Moreover, the 12-hour daylength promoted earlier flower formation and higher flower count compared with the 6- to 8-hour daylengths. Longer daylengths neither accelerated flowering formation nor enhanced total flower count. In conclusion, 8 hours of saturating $P P F$ at $200 \mu \mathrm{mol} \cdot \mathrm{m}^{-2} \cdot \mathrm{s}^{-1}$ and a 12-hour daylength are sufficient for maximizing photosynthesis and flower production in 'TS97' plants.
\end{abstract}

Phalaenopsis orchids have become one of the most valuable potted ornamental plants around the world. According to the U.S. Department Agriculture's (USDA's) Floriculture Crops Summary, potted orchids account for \$191 million in wholesale revenue in 2011 (USDA, 2012) and the value is projected to increase by $15 \%$ annually in which $70 \%$ of these orchids are Phalaenopsis and imported from Taiwan. Both Taiwanese and U.S. growers have been focused on optimizing the orchid production to reduce the growing period and forcing time before and after overseas shipping, respectively. The emergence of an inflorescence and the quality of flowers are highly correlated with high levels of carbohydrates stored in orchid leaves (Hou et al., 2011; Konow and Wang, 2001; Lin and Hsu, 2004). The pre-shipment carbohydrate status is also critical for flowering forcing in Phalaenopsis orchids (Hou et al., 2011). Carbohydrates from photosynthesis account for $90 \%$ of the dry weight in most crops and light irradiance is often a key factor for maximal photosynthesis. In Phalaenopsis, low irradiance significantly slows the growth rate at all developmental stages and delays flower formation as well as reduces flower count (Lee, 2000; Lin and Lee, 1998; Wang, 1995). Thus, maximizing

Received for publication 24 July 2012. Accepted for publication 24 Sept. 2012. We thank the financial support from the National Science Council (NSC-1012313-B-006-001-MY3) and the constructive comments on the article from Dr. Tong-Seung Tseng, Dr. Kate Dreher, and Dr. Yao-Chien Alex Chang.

${ }^{1}$ Corresponding author. E-mail: wjguo@mail.ncku.edu.tw. the photosynthetic carbon fixation with optimal light irradiance is important for best growth and flowering in Phalaenopsis orchids.

Phalaenopsis amabilis 'TS97' has many medium-sized flowers per inflorescence, a fast leaf production rate, and a short juvenile phase (Christenson, 2001). These physiological characteristics of traits have made 'TS97' one of the most important indigenous commercial cultivars in Taiwan and it represents a production model for most Phalaenopsis hybrids. Therefore, detailed studies on the photosynthetic performance of 'TS97' would provide a practical index for producing high-quality Phalaenopsis.

The TS97 cultivar, similar to other Phalaenopsis hybrids, performed the typical crassulacean acid metabolism (CAM) photosynthetic pathway, in which $\mathrm{CO}_{2}$ is absorbed primarily during the night (Phase I) and fixed into malate or titratable acid. The stored acid is subsequently metabolized during the day through Calvin cycle to produce sugars (Phases II to III) (Cushman and Bohnert, 1999; Endo and Ikusima, 1989; Guo and Lee, 2006). A small amount of $\mathrm{CO}_{2}$ uptake also occurs $8 \mathrm{~h}$ after plants are exposed to light (late afternoon, Phase IV) when $\mathrm{CO}_{2}$ is fixed through the $\mathrm{C}_{3}$ pathway accompanied by photorespiration (Cushman and Bohnert, 1999; Guo and Lee, 2006). Studies showed that the daily total $\mathrm{CO}_{2}$ uptake, representing photosynthetic ability in a CAM plant, increased with maturation of leaves and reached the maximum at a leaf age of $80 \mathrm{~d}$ and then remained constant and declined after $240 \mathrm{~d}$ (Guo and 
Lee, 2006). The photosynthetic ability in a leaf is independent of plant age. The optimal temperature for photosynthetic fixation in 'TS97' leaves ranges from $29 / 25$ to $32 / 28{ }^{\circ} \mathrm{C}$ day/ night temperature (Guo and Lee, 2006) that correlates well with the field practice for optimal vegetative growth in Phalaenopsis plants (Lee, 2000; Lin and Lee, 1988).

Light has been shown to regulate CAM photosynthesis (Kluge and Ting, 1978); however, the impacts of light intensity and duration on photosynthetic ability in a Phalaenopsis leaf are not well established. A Phalaenopsis hybrid demonstrated that the net daily $\mathrm{CO}_{2}$ assimilation will saturate at 130 $\mu \mathrm{mol} \cdot \mathrm{m}^{-2} \cdot \mathrm{s}^{-1} \mathrm{PPF}$ (Ota et al., 1991), which is much lower than the level used in field production, normally ranging between 280 and $380 \mu \mathrm{mol} \cdot \mathrm{m}^{-2} \cdot \mathrm{s}^{-1}$ PPF (Chen and Wang, 1996). Analysis of chlorophyll fluorescence in Phalaenopsis leaves suggested that photosynthesis is not saturated until above 300 $\mu \mathrm{mol} \cdot \mathrm{m}^{-2} \cdot \mathrm{s}^{-1} P P F$ (Lin and Hsu, 2004; Lootens and Heursel, 1998). However, chlorophyll fluorescence only represents the maximum photochemical efficiency in the chloroplast and does not linearly correlate with total carbon fixation (Maxwell and Johnson, 2000). On the other hand, during orchid production in Taiwan, short-term, low-light conditions often occur as a result of afternoon showers in the summers, which in turn complicate the greenhouse management for maximal light irradiance. In addition, during the winter production season, Phalaenopsis plants often develop leaves under relatively low-light irradiance. It is still not known how the short-term or long-term lowlight exposure affect CAM fixation ability in Phalaenopsis leaves. Thus, the light requirement for maximal photosynthetic ability in 'TS97' requires further examination.

Daylength also affects photosynthetic capacities in CAM plants. In general, short daylengths promote nocturnal stomata opening and increase total nighttime $\mathrm{CO}_{2}$ fixation as observed in Kalanchoe blossfeldiana (Queiroz, 1974). In contrast, long daylengths promote daytime $\mathrm{CO}_{2}$ uptake and inhibit nighttime $\mathrm{CO}_{2}$ fixation resulting in limited growth, as observed in Ananas comosus and Dendrobium ekapol (Nose et al., 1986; Sekizuka et al., 1995). However, in some obligate CAM plants, daylength only affects the rhythm of $\mathrm{CO}_{2}$ uptake but does not affect total photosynthetic capacity (Brulfert et al., 1982). Because the relationship between daylength and CAM photosynthesis varies among species, the effects of different daylengths on photosynthesis in Phalaenopsis leaves require further verification.

Therefore, in this study we determined the effect of light intensity on different aspects of photosynthetic efficiency, including diurnal $\mathrm{CO}_{2}$ uptake rate, total $\mathrm{CO}_{2}$ uptake capacity, malate fixation, and PSII quantum yield in 'TS97' leaves, and investigated the effects of low-light adaption, low-light exposure, and daylength on photosynthetic ability in leaves and on flower development.

\section{Materials and Methods}

Plant materials. Mature plants of the 'TS97' clone of P. amabilis, 14 months after deflasking, were purchased from Taiwan Sugar Corp. (Tainan, Taiwan). Plants were transplanted into 10.5 -cm plastic pots with sphagnum moss as the medium. Generally, plants had five or six mature leaves, which were 10 to $13 \mathrm{~cm}$ in length and 5.5 to $6 \mathrm{~cm}$ in width. Plants were grown in a greenhouse under natural daylength and light exposure for one to two months before being used in various experiments.
The cooling and shading systems in the greenhouse were programmed to maintain an average day/night temperature of $30 / 25^{\circ} \mathrm{C}$ and a maximum $P P F$ of $300 \mu \mathrm{mol} \cdot \mathrm{m}^{-2} \cdot \mathrm{s}^{-1}$. Plants were watered as needed and fertilized weekly with $20 \mathrm{~N}-8.6 \mathrm{P}-16.6 \mathrm{~K}$ soluble fertilizer (Peters; Scotts, Marysville, $\mathrm{OH}$ ) at a concentration of $1 \mathrm{~g} \cdot \mathrm{L}^{-1}$. To provide additional microelements, plants were also fertilized monthly with half-strength Johnson's solution without the $20 \mathrm{~N}-8.6 \mathrm{P}-16.6 \mathrm{~K}$ fertilizer (Johnson et al., 1957). All the experiments were performed in controlled growth chambers and the default growth conditions were 200 $\mu \mathrm{mol} \cdot \mathrm{m}^{-2} \cdot \mathrm{s}^{-1} P P F$ and $30 / 25^{\circ} \mathrm{C}$ day/night temperature with a 12-h daylength (0700 to $1900 \mathrm{HR}$ ) unless otherwise noted.

Measurement of DiURNal net $\mathrm{CO}_{2}$ UPTAKe Rate. The net $\mathrm{CO}_{2}$ uptake rate was measured using a portable photosynthesis system (LI-6200; LI-COR, Lincoln, NE) as described previously (Guo and Lee, 2006). In short, the second leaf from the apex was kept in a $250-\mathrm{mL}$ transparent chamber for 20 to $30 \mathrm{~s}$ to equilibrate with the ambient microconditions. The light irradiance was provided directly from the growth chamber. Then the net $\mathrm{CO}_{2}$ uptake was recorded every $4 \mathrm{~s}$ and the average from three consecutive recordings was used to calculate the net $\mathrm{CO}_{2}$ uptake rate. The leaf area covered in the chamber was drawn on a paper and determined with an area meter (LI-3100; LI-COR). These measurements were repeated hourly or every $2 \mathrm{~h}$ during a 24-h period to establish a diurnal net $\mathrm{CO}_{2}$ uptake curve. The net daytime, nighttime, and daily total $\mathrm{CO}_{2}$ uptake were calculated by integrating the diurnal uptake curves (Nobel, 1991). Leaf and air temperature, $P P F$, and stomatal conductance of the analyzed leaves were also measured concomitantly.

Measurement of LeAF CHLOROPHYLl FLUORESCENCE. The leaf chlorophyll fluorescence of the attached leaves that were used to measure diurnal net $\mathrm{CO}_{2}$ uptake rates was measured by a portable fluorometer (PEA; Hansatech, Norfolk, U.K.). In all the experiments, the measurements were performed $1 \mathrm{~h}$ after the light period started (usually 0800 to $0830 \mathrm{HR}$ ). The chosen leaf spots were completely darkened with the leaf clips for 10 min to allow the relaxation of fluorescence quenching associated with thylakoid membrane energization (Maxwell and Johnson, 2000). Preliminary experiments showed that preincubation for $10 \mathrm{~min}$ in darkness was enough to obtain maximum fluorescence. Then the minimal fluorescence, $F_{o}$, was determined, whereas the maximal fluorescence, $F_{m}$, was also measured after a saturating pulse of red light. An increase in the $\mathrm{F}_{\mathrm{o}}$ value represents a potential damage of the PSII reaction center that usually correlates with a decrease in the $F_{m}$ value, indicating a reduction in maximal photochemical fluorescence quenching (Bolhar-Nordenkampf et al., 1989; Maxwell and Johnson, 2000). The variable fluorescence $F_{v}$, where $F_{v}=F_{m}-$ $F_{o}$, and the fluorescence ratio, $F_{v} / F_{m}$, were then calculated, representing current PSII photochemical efficiency. Therefore, a decline in $\mathrm{F}_{\mathrm{v}} / \mathrm{F}_{\mathrm{m}}$ is an indicator of photoinhibitory damage to PSII under environmental stresses (Bolhar-Nordenkampf et al., 1989; Maxwell and Johnson, 2000).

Measurement of malate and titratable acidity. The changes in malate and titratable acid concentration during the night are indicators of nocturnal carbon fixation in CAM plants (Osmond et al., 1991). To analyze the concentration of the accumulated acids, two leaf discs, $\approx 0.1 \mathrm{~g}$ each in fresh weight (FW), were collected from the leaf 30 min before the light (predawn) and the dark period (pre-dusk). Samples were frozen immediately in liquid $\mathrm{N}_{2}$ and stored at $-50{ }^{\circ} \mathrm{C}$ for further analyses as described previously (Guo and Lee, 2006). In short, 
the frozen tissues were ground in a prechilled mortar with $5 \mathrm{~mL}$ of distilled water. The crude extracts were boiled for $10 \mathrm{~min}$, cooled, and centrifuged at $10,000 \mathrm{~g}_{\mathrm{n}}$ for $5 \mathrm{~min}$. To analyze the malate concentration, $60 \mu \mathrm{L}$ of the supernatant was added to the reaction mixture, which contained $0.9 \mu \mathrm{L}$ of reaction buffer, $20 \mu \mathrm{L}$ of malate-dehydrogenase $(250 \mathrm{U} / \mathrm{mL})$, and $20 \mu \mathrm{L}$ of $30 \mathrm{~mm}$ nicotinamide adenine dinucleotide. The reaction mixtures were incubated at $30{ }^{\circ} \mathrm{C}$ for $1 \mathrm{~h}$ and then the absorbance at $340 \mathrm{~nm}$ was determined by an ultraviolet/visible light spectrophotometer (U-1800; Hitachi, Tokyo, Japan). The malate concentration was determined according to standard curves and expressed as micromoles per gram FW. To analyze the titratable acidity, $4 \mathrm{~mL}$ of the supernatant was titrated with $0.02 \mathrm{~N} \mathrm{NaOH}$ (Merck, Whitehouse Station, NJ) to an end point of $\mathrm{pH} 8.3$ to neutralize all the acidity. The amount of $\mathrm{NaOH}$ consumed was used to calculate the concentration of the titratable acid, expressed as micromoles $\mathrm{H}^{+}$per gram $\mathrm{FW}$.

EFFECT OF Light INTENSITY. Mature plants were first normalized by exposure to the default growth conditions (see "Plant Materials") in a controlled growth chamber for $2 \mathrm{~d}$. Then plants were exposed to $30 / 25{ }^{\circ} \mathrm{C}$ day/night temperature and a 12-h daylength with one of the following levels of PPF: 0 , $25,90,125,220,325$, and $450 \mu \mathrm{mol} \cdot \mathrm{m}^{-2} \cdot \mathrm{s}^{-1}$, which were averages measured on the second leaf from the apex (the newly matured leaf). After $5 \mathrm{~d}$ in the light treatment, the diurnal net $\mathrm{CO}_{2}$ uptake rate of the same second leaf was measured. Leaf chlorophyll fluorescence, diurnal changes of malate, and titratable acid level were also determined on the same leaves at the same time.

EFFECT OF LOW-Light ADAPTION. To investigate how lowlight adaption (LLA) would affect the $\mathrm{CO}_{2}$ uptake ability in 'TS97' leaves, the diurnal net $\mathrm{CO}_{2}$ uptake rate of LLA leaves was measured. When new emerging leaves had reached 3 to $4 \mathrm{~cm}$ in the greenhouse conditions (see "Plant Materials"), plants were transferred into a controlled growth chamber with $12 \mathrm{~h}$ of $30 \mu \mathrm{mol} \cdot \mathrm{m}^{-2} \cdot \mathrm{s}^{-1} \mathrm{PPF}$ and $30 / 25^{\circ} \mathrm{C}$ day/night temperature for further development to maturity. After the leaves were fully mature under the low PPF (12 to $14 \mathrm{~cm}$ in length, after $\approx 70 \mathrm{~d}$ ), the diurnal changes of net $\mathrm{CO}_{2}$ uptake rate in response to $0,22,125,207$, and $307 \mu \mathrm{mol} \cdot \mathrm{m}^{-2} \cdot \mathrm{s}^{-1} P P F$ were determined as described in the section of "Effect of Light Intensity."

EFFECT OF LOW-LIGHT EXPOSURE. To investigate how the photosynthetic ability was affected by low-light exposure (LLE) during the day, mature plants were transferred from the greenhouse condition to a controlled growth chamber with $30 / 25^{\circ} \mathrm{C}$ day/night temperature and a 4-h low-light exposure (30 $\left.\mu \mathrm{mol} \cdot \mathrm{m}^{-2} \cdot \mathrm{s}^{-1} \mathrm{PPF}\right)$ during different time periods: in the morning [AL (0700 to $1100 \mathrm{HR})$ ], at noon [ML (1100 to $1500 \mathrm{HR})$ ], and in the afternoon [PL (1500 to $1900 \mathrm{HR})$ ]. All the LLE treatments were under a 12-h daylength (0700 to $1900 \mathrm{HR})$ with $8 \mathrm{~h}$ of saturating light $\left(200 \mu \mathrm{mol} \cdot \mathrm{m}^{-2} \cdot \mathrm{s}^{-1} \mathrm{PPF}\right)$. These plants were also compared with those grown under a 12-h saturating light condition $\left(200 \mu \mathrm{mol} \cdot \mathrm{m}^{-2} \cdot \mathrm{s}^{-1} P P F, \mathrm{HH}\right)$. After 1 week of treatment, the diurnal $\mathrm{CO}_{2}$ uptake curves, leaf chlorophyll fluorescence, and diurnal changes of malate and titratable acid were measured under the same treated conditions (AL, ML, PL, HH).

EfFect of DaYlength. Plants were grown under a daylength of $8 \mathrm{~h}(1100$ to $1900 \mathrm{HR}), 12 \mathrm{~h}(0730$ to $1930 \mathrm{HR})$, or $16 \mathrm{~h}(0330$ to $1930 \mathrm{HR}$ ), respectively, with a day/night temperature of $30 / 25^{\circ} \mathrm{C}$. To prevent yellowing symptoms resulting from the heating effect of long saturating irradiance under a 16-h daylength and $30{ }^{\circ} \mathrm{C}$ temperature (observed previously), the $90 \%$ saturating $P P F, 110 \mu \mathrm{mol} \cdot \mathrm{m}^{-2} \cdot \mathrm{s}^{-1}$ (deduced from Fig. 1B), was used. After 1 week of treatment, the diurnal net $\mathrm{CO}_{2}$ uptake rate of the second leaf was measured and the 24-h total carbon
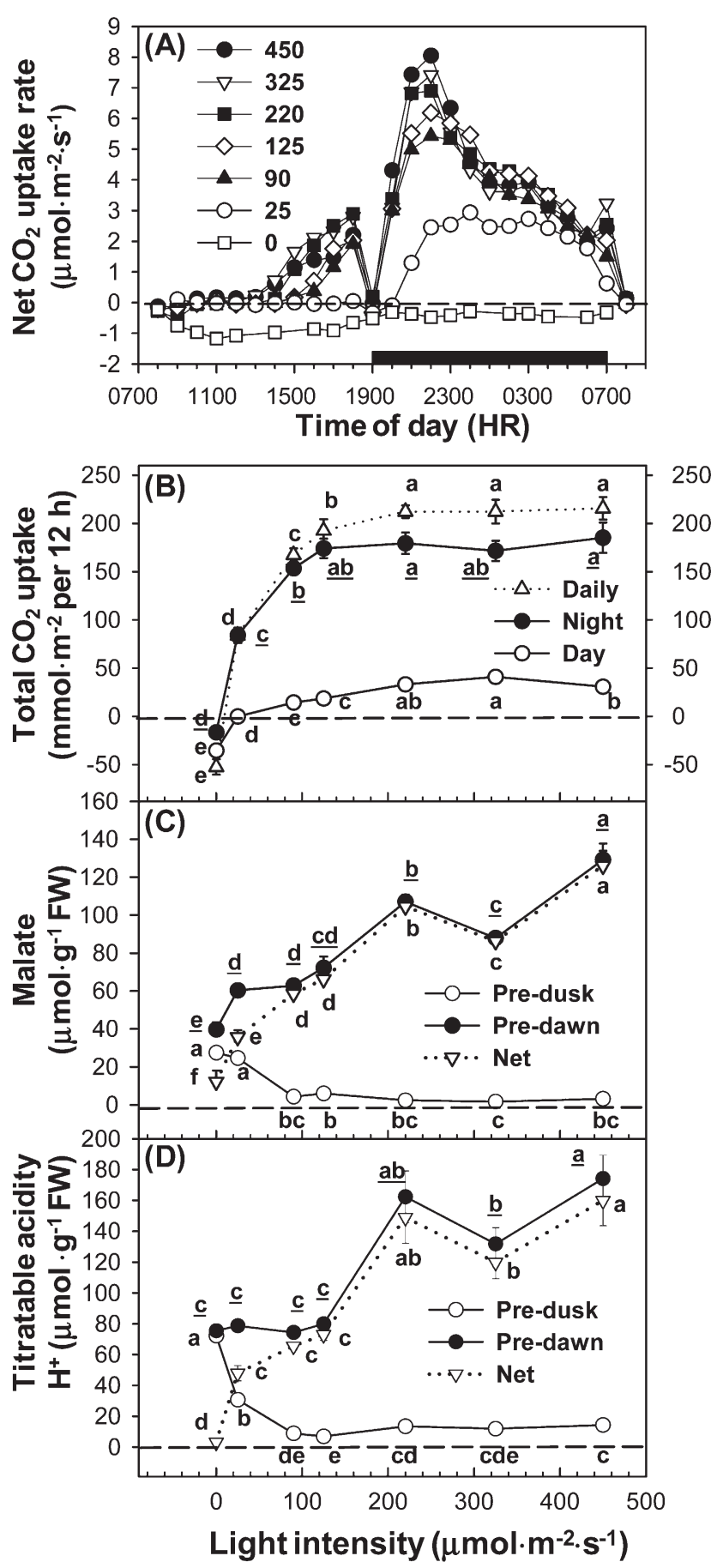

Fig. 1. Effects of light intensity on (A) diurnal changes of net $\mathrm{CO}_{2}$ uptake rate and (B) total $\mathrm{CO}_{2}$ uptake during the day $(\bigcirc)$, during the night $(\mathbf{O})$, and over a daily 24-h period $(\triangle)$, in Phalaenopsis amabilis 'TS97' leaves. The photosynthetic photon flux $\left(P P F ; \mu \mathrm{mol} \cdot \mathrm{m}^{-2} \cdot \mathrm{s}^{-1}\right)$ measured on the leaves were shown in the left corner (A). Levels of $(\mathbf{C})$ malate and (D) titratable acidity at pre-dusk $(\bigcirc)$, predawn $(\mathbf{O})$, and net nocturnal accumulation $(\nabla)$ were also measured from the same leaves in A. Results are (A) means or $(\mathbf{B}-\mathbf{D})$ means \pm SE $(\mathrm{n}=3)$; $(\mathbf{\square})$ : darkness. Means with the same letter are not significantly different at $P<0.05$ by Duncan's multiple range test. The underlined letters represent differences in the (B) nighttime uptake and the (C-D) pre-dawn acid concentration. 
uptake was calculated. To study the effect of daylength on the flower formation, mature plants were grown under 6-, 8-, 10-, 12-, 14-, and 16-h daylength cycles with a cool day/night temperature of $23 / 18^{\circ} \mathrm{C}$ and a $P P F$ at $173 \mu \mathrm{mol} \cdot \mathrm{m}^{-2} \cdot \mathrm{s}^{-1}$, which was the average from all the daylength treatments. In each treatment, the PPF on the top second leaves of five 'TS97' plants was measured. These growth conditions were applied through the entire period of the experiments to induce flower formation and allow flower anthesis (Lin, 1994). The date of flower stalk emergence (greater than $1 \mathrm{~cm}$ ), visible flower bud, and anthesis was recorded. After four months of flower forcing, the total flower count was recorded.

\section{Results}

EFFECT OF LIGHT INTENSITY ON NORMALLY GROWN LEAVES. Under various $P P F$, 'TS97' leaves exhibited a typical CAM photosynthesis pattern (Fig. 1A). Most $\mathrm{CO}_{2}$ uptake in 'TS97' leaves occurred mainly during the dark period (Phase I) and the nocturnal $\mathrm{CO}_{2}$ uptake rate increased with light intensity. High $P P F$ between $\approx 200$ and $450 \mu \mathrm{mol} \cdot \mathrm{m}^{-2} \cdot \mathrm{s}^{-1}$ resulted in the highest nocturnal $\mathrm{CO}_{2}$ uptake rate $\left(7\right.$ to $\left.8 \mu \mathrm{mol} \cdot \mathrm{m}^{-2} \cdot \mathrm{s}^{-1}\right)$ and earlier onset of $\mathrm{CO}_{2}$ uptake in the afternoon (Phase IV). For example, the treatment of $325 \mu \mathrm{mol} \cdot \mathrm{m}^{-2} \cdot \mathrm{s}^{-1} P P F$ enabled $\mathrm{CO}_{2}$ uptake $5 \mathrm{~h}$ before the dark period compared with $3 \mathrm{~h}$ under the $90 \mu \mathrm{mol} \cdot \mathrm{m}^{-2} \cdot \mathrm{s}^{-1} P P F$. When exposed to extremely low $P P F$ $\left(25 \mu \mathrm{mol} \cdot \mathrm{m}^{-2} \cdot \mathrm{s}^{-1}\right)$, both the daytime and nocturnal $\mathrm{CO}_{2}$ uptake rates were significantly reduced, especially $\mathrm{CO}_{2}$ uptake in the afternoon, which completely diminished. Moreover, a significant amount of $\mathrm{CO}_{2}$ was released during the day when grown under $0 \mu \mathrm{mol} \cdot \mathrm{m}^{-2} \cdot \mathrm{s}^{-1} P P F$.

Because the daily total $\mathrm{CO}_{2}$ uptake represents the efficiency of CAM photosynthesis, daytime, nighttime, and daily total $\mathrm{CO}_{2}$ uptake were calculated from Figure 1A (Fig. 1B). A $P P F$ at 125 $\mu \mathrm{mol} \cdot \mathrm{m}^{-2} \cdot \mathrm{s}^{-1}$ resulted in the maximal nighttime $\mathrm{CO}_{2}$ uptake and $90 \%$ of the daily total $\mathrm{CO}_{2}$ uptake. A PPF above $\approx 200 \mu \mathrm{mol} \cdot \mathrm{m}^{-2} \cdot \mathrm{s}^{-1}$ enabled the maximal daily and daytime total $\mathrm{CO}_{2}$ uptake at $\approx 210 \mathrm{mmol} \cdot \mathrm{m}^{-2} \cdot \mathrm{d}^{-1}$ and $30 \mathrm{mmol} \cdot \mathrm{m}^{-2}$ per $12 \mathrm{~h}$, respectively. These data indicated that carbon fixation during the day (Phase IV) required higher saturating irradiance than that during the night. The 'TS97' leaves exhibited low-light requirement, 25 and $\approx 5 \mu \mathrm{mol} \cdot \mathrm{m}^{-2} \cdot \mathrm{s}^{-1} P P F$, for compensating respirational carbon loss during the day and the night, respectively.

Because diurnal net accumulations of malate and titratable acid represent nocturnal carbon fixation capacity in CAM photosynthesis, we further determined levels of the acids before (pre-dusk) and after (pre-dawn) the dark period. The net accumulation of both malate and titratable acid increased with $P P F$ (Fig. 1C-D) and can be divided into two stages. Under low $P P F\left(90 \mu \mathrm{mol} \cdot \mathrm{m}^{-2} \cdot \mathrm{s}^{-1}\right.$ or less $)$, the pre-dusk acid level significantly decreased with light intensities along with little change in the pre-dawn acid level. When exposed to high $P P F$ (greater than $\left.125 \mu \mathrm{mol} \cdot \mathrm{m}^{-2} \cdot \mathrm{s}^{-1}\right)$, the pre-dawn acid concentration greatly increased, whereas the pre-dusk acid level remained similar. At $325 \mu \mathrm{mol} \cdot \mathrm{m}^{-2} \cdot \mathrm{s}^{-1} P P F$, the capacity of nocturnal malate fixation decreased, whereas the level of malate increased again after exposure to $450 \mu \mathrm{mol} \cdot \mathrm{m}^{-2} \cdot \mathrm{s}^{-1} P P F$ (Fig. 1C). The concentration of titratable acidity remained similar between 200 and $450 \mu \mathrm{mol} \cdot \mathrm{m}^{-2} \cdot \mathrm{s}^{-1} P P F$ (Fig. 1D).

When grown at a $P P F$ below $125 \mu \mathrm{mol} \cdot \mathrm{m}^{-2} \cdot \mathrm{s}^{-1}$, no significant differences were observed in the values of $\mathrm{F}_{\mathrm{v}} / \mathrm{F}_{\mathrm{m}}, \mathrm{F}_{\mathrm{o}}$, and $\mathrm{F}_{\mathrm{m}}$ in 'TS97' leaves (Fig. 2A-B). The $\mathrm{F}_{\mathrm{v}} / \mathrm{F}_{\mathrm{m}}$ values ranged

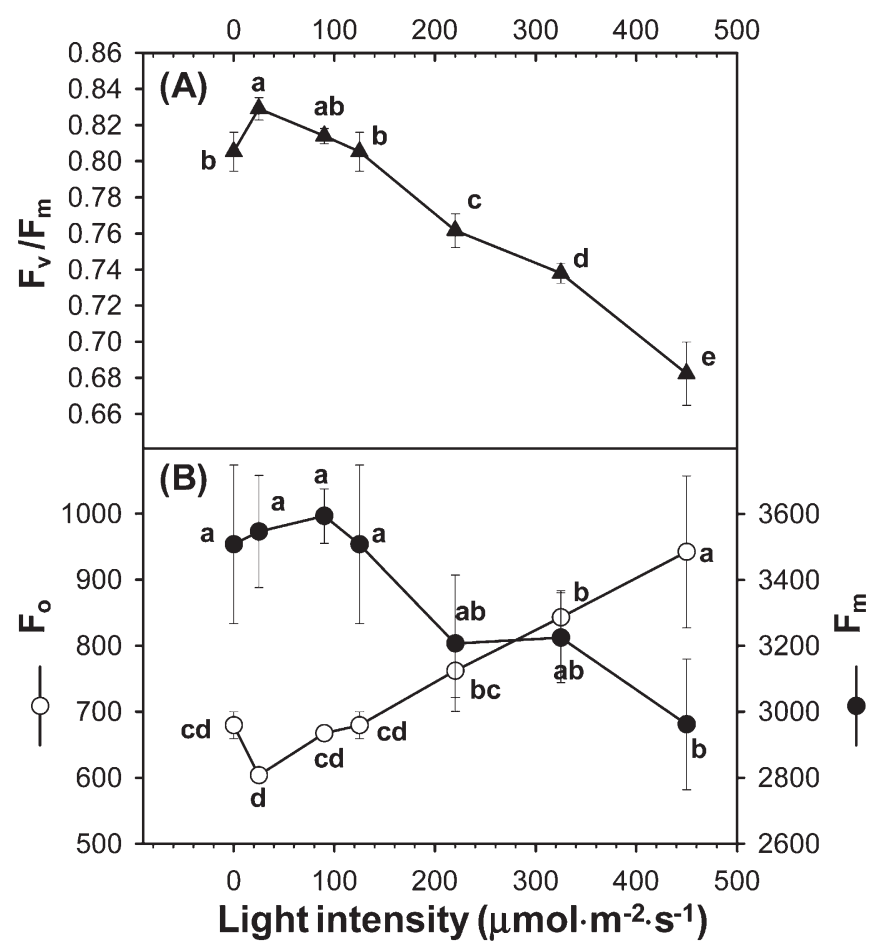

Fig. 2. Effects of light intensity on (A) the maximal photosystem II (PSII) efficiency, $\mathrm{F}_{\mathrm{v}} / \mathrm{F}_{\mathrm{m}}$ and $(\mathbf{B})$ initial and maximum chlorophyll fluorescence, $\mathrm{F}_{\mathrm{o}}(\mathrm{O})$ and $\mathrm{F}_{\mathrm{m}}(\mathbf{O})$, in Phalaenopsis amabilis 'TS97' leaves that are the same as those measured in Figure 1. Results are means \pm SE $(n=3)$. Means with the same letter are not significantly different at $P<0.05$ by Duncan's multiple range test.

between 0.80 and 0.83 , suggesting high PSII quantum efficiency. However, when exposed to a PPF higher than 325 $\mu \mathrm{mol} \cdot \mathrm{m}^{-2} \cdot \mathrm{s}^{-1}$, the $\mathrm{F}_{\mathrm{o}}$ value increased along with a decrease in the $\mathrm{F}_{\mathrm{m}}$ value, indicating potential damage in PSII reaction centers. A PPF at 325 and $450 \mu \mathrm{mol} \cdot \mathrm{m}^{-2} \cdot \mathrm{s}^{-1}$ had reduced the $\mathrm{F}_{\mathrm{v}} / \mathrm{F}_{\mathrm{m}}$ values to 0.68 to 0.74 lower than the optimal, demonstrating that PSII efficiency has been significantly reduced. The leaves appeared less green when plants were grown under $450 \mu \mathrm{mol} \cdot \mathrm{m}^{-2} \cdot \mathrm{s}^{-1} P P F$ for 1 week (data not shown).

EFfect of Low-light adaptation. The LLA leaves exhibited similar CAM fixation patterns as those developed under saturating irradiance in the greenhouse (normal leaves) (Figs. 1A and 3A). However, when exposed to a saturating PPF $\left(200 \mu \mathrm{mol} \cdot \mathrm{m}^{-2} \cdot \mathrm{s}^{-1}\right)$, the maximum nocturnal $\mathrm{CO}_{2}$ uptake rate was only $4.2 \mu \mathrm{mol} \mathrm{CO}_{2} / \mathrm{m}^{2} / \mathrm{s}$ in the LLA leaf (Fig. 3A). In particular, when exposed to a low $P P F$ of 22 to 125 $\mu \mathrm{mol} \cdot \mathrm{m}^{-2} \cdot \mathrm{s}^{-1}$, the LLA leaves showed marked delays of daytime or nighttime $\mathrm{CO}_{2}$ uptake compared with normal leaves (Figs. 1A and 3A). Moreover, darkness resulted in continuous net release of $\mathrm{CO}_{2}$. Compared with the normal leaves, the daily total $\mathrm{CO}_{2}$ uptake in the LLA leaves saturated at a lower $P P F$, $125 \mu \mathrm{mol} \cdot \mathrm{m}^{-2} \cdot \mathrm{s}^{-1}$, and the maximal daily total carbon fixation was $\approx 150 \mathrm{mmol} \cdot \mathrm{m}^{-2} \cdot \mathrm{d}^{-1}$ of $\mathrm{CO}_{2}$. In contrast, the daytime total $\mathrm{CO}_{2}$ uptake saturated at a higher $P P F$, greater than 300 $\mu \mathrm{mol} \cdot \mathrm{m}^{-2} \cdot \mathrm{s}^{-1}$ (Figs. 1B and 3B). In addition, the LLA leaves required a higher $P P F$ than the normal leaves to enable positive carbon fixation during the day $\left(\approx 80 \mu \mathrm{mol} \cdot \mathrm{m}^{-2} \cdot \mathrm{s}^{-1} P P F\right)$ and the night $\left(\approx 20 \mu \mathrm{mol} \cdot \mathrm{m}^{-2} \cdot \mathrm{s}^{-1} P P F\right)$, suggesting that the efficiency to use the light energy had been reduced when leaves developed under a low $P P F$. 

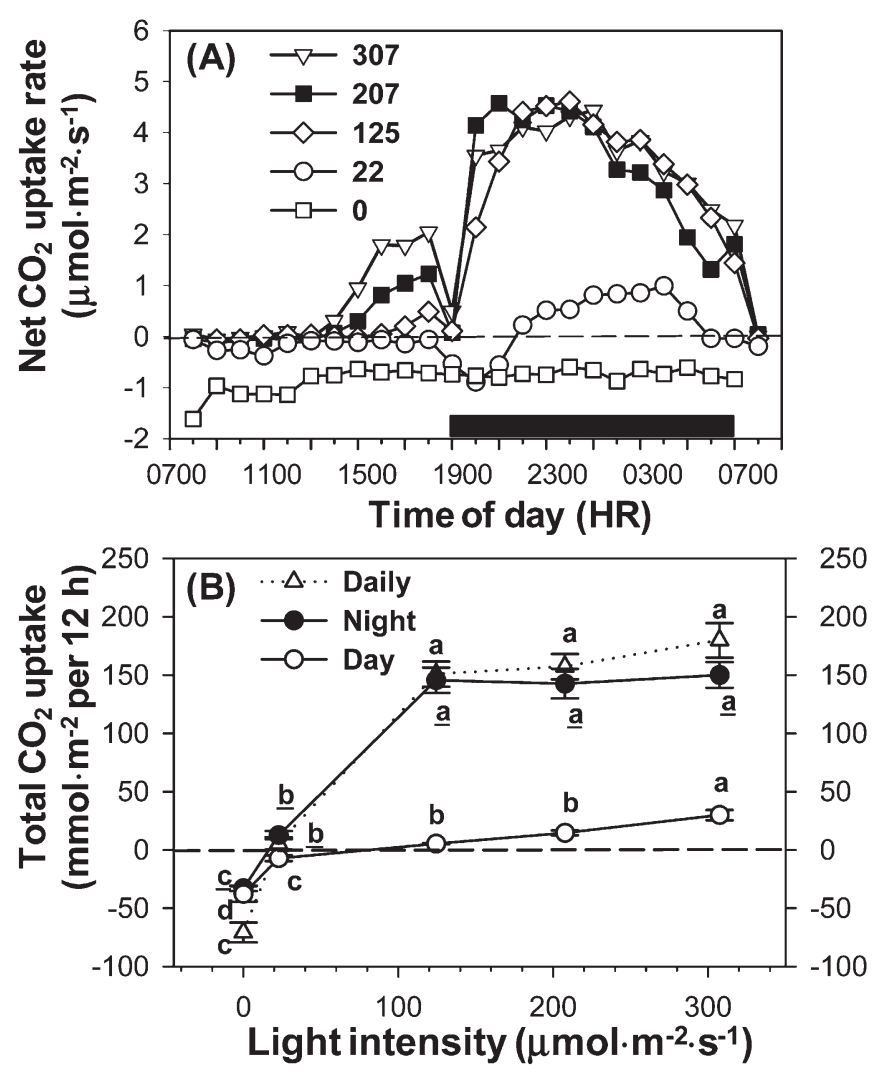

Fig. 3. Effects of low-light adaption on (A) diurnal changes of net $\mathrm{CO}_{2}$ uptake rate and $(\mathbf{B})$ total $\mathrm{CO}_{2}$ uptake during the day $(\bigcirc)$, during the night $(\mathbf{O})$, and over a daily 24-h period $(\triangle)$ in Phalaenopsis amabilis 'TS97' leaves that were developed under $30 \mu \mathrm{mol} \cdot \mathrm{m}^{-2} \cdot \mathrm{s}^{-1}$ photosynthetic photon flux $(P P F)$ until mature. The $P P F\left(\mu \mathrm{mol} \cdot \mathrm{m}^{-2} \cdot \mathrm{s}^{-1}\right)$ measured on the leaves were shown in the left corner $(\mathbf{A})$. Results are (A) means or $(\mathbf{B})$ means $\pm \mathrm{SE}(\mathrm{n}=3)$; ( $\mathbf{(})$ : darkness. Means with the same letter are not significantly different at $P<0.05$ by Duncan's multiple range test. The underlined letters represent differences in the nighttime uptake (B)

EFFECT OF LOW-LIGHT EXPOSURE. To investigate how LLE affects photosynthetic ability in Phalaenopsis, the 'TS97' leaves were analyzed after being subjected to $4 \mathrm{~h}$ of LLE (30 $\left.\mu \mathrm{mol} \cdot \mathrm{m}^{-2} \cdot \mathrm{s}^{-1} P P F\right)$ during various times of the day, in the morning, at noon, and in the afternoon, and compared with those grown under $12 \mathrm{~h}$ of saturating light. Although the diurnal $\mathrm{CO}_{2}$ uptake rhythms were unaffected (Fig. 4A), LLE during the day, regardless of its timing, delayed afternoon $\mathrm{CO}_{2}$ uptake by $2 \mathrm{~h}$ (Phase IV) in 'TS97' leaves compared with the control condition (HH) (Fig. 4A). That in turn resulted in reduced levels of daytime total $\mathrm{CO}_{2}$ uptake by almost $50 \%$ (Fig. 4B). Nevertheless, the nocturnal $\mathrm{CO}_{2}$ uptake rate, nighttime total $\mathrm{CO}_{2}$ uptake, and net malate accumulation in the LLE leaves were all similar to control leaves (HH) (Fig. 4B; Table 1). The daily total $\mathrm{CO}_{2}$ uptake was slightly lower in the LLE leaves but not statistically different from the control leaves $(\mathrm{HH})$. The $\mathrm{F}_{\mathrm{v}} / \mathrm{F}_{\mathrm{m}}, \mathrm{F}_{\mathrm{m}}$, and $\mathrm{F}_{\mathrm{o}}$ values were also similar among treatments except that higher $\mathrm{F}_{\mathrm{v}} / \mathrm{F}_{\mathrm{m}}$ ratios were observed in the PL-treated leaves. Interestingly, all of the LLE treatments significantly increased the concentration of net nocturnal titratable acidity compared with that in the control leaves (Table 1).

EFFECT OF DAYLENGTH. To understand how daylength affects CAM phososythesis in Phalaenopsis, 'TS97' leaves were exposed to 8-, 12-, or 16-h daylength cycles for 1 week with
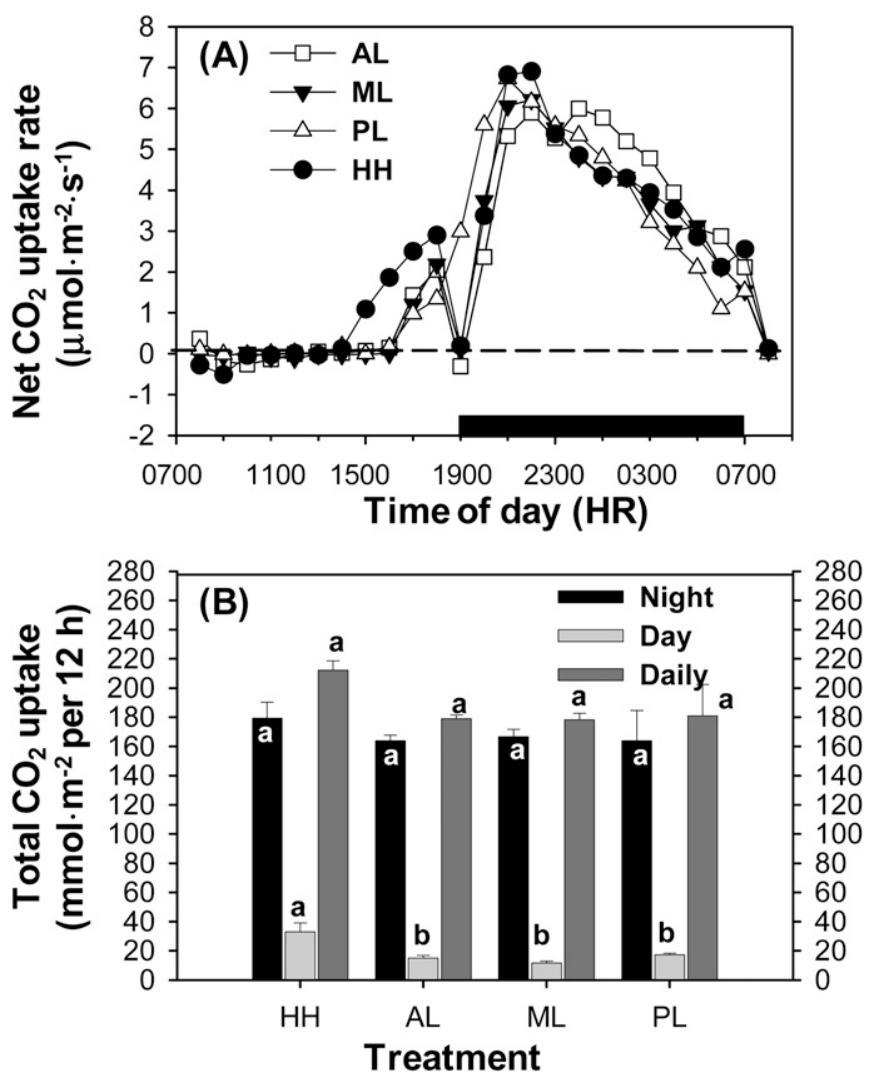

Fig. 4. Effect of low-light exposure for $4 \mathrm{~h}$ on (A) diurnal changes of net $\mathrm{CO}_{2}$ uptake rate and (B) total $\mathrm{CO}_{2}$ uptake during the night (black), during the day (gray), and over a 24-h period (daily) (dark gray) in Phalaenopsis amabilis 'TS97' leaves. AL, ML, and PL represent low-light exposure $\left(30 \mu \mathrm{mol} \cdot \mathrm{m}^{-2} \cdot \mathrm{s}^{-1}\right.$ $P P F)$ in the morning (0700 to $1100 \mathrm{HR}$ ), at noon (1100 to $1500 \mathrm{HR}$ ), and in the afternoon (1500 to $1900 \mathrm{HR}$ ), respectively, under a 12-h daylengh. $\mathrm{HH}$ indicates control leaves grown under saturating light for $12 \mathrm{~h}$. Results are (A) means or (B) means $\pm \mathrm{SE}(\mathrm{n}=3)$; ( $\mathbf{\square})$ : darkness. Means with the same letter are not significantly different at $P<0.05$ by Duncan's multiple range test.

$110 \mu \mathrm{mol} \cdot \mathrm{m}^{-2} \cdot \mathrm{s}^{-1} P P F$ before measuring the diurnal $\mathrm{CO}_{2}$ uptake rates. The 'TS97' leaves performed similar CAM rhythms, absorbing $\mathrm{CO}_{2}$ mainly during the night, under all the photoperiods (Fig. $5 \mathrm{~A}-\mathrm{C}$ ). Compared with that under the 12-h daylength, the daytime $\mathrm{CO}_{2}$ uptake rates and capacities in leaves were significantly reduced under the 8-h daylength (Figs. 5A, 5B, and 5D). Moreover, the nighttime $\mathrm{CO}_{2}$ uptake in 'TS97' leaves was diminished after $10 \mathrm{~h}$ in the dark period when exposed to a daylength of $8 \mathrm{~h}$ (Fig. 5A). As a result of a shorter period of darkness, the 16-h daylength cycle caused less nocturnal $\mathrm{CO}_{2}$ uptake than the 12-h daylength cycle (Fig. 5B-D). Overall, the 12-h daylength resulted in the highest daily total $\mathrm{CO}_{2}$ fixation and longer daylength did not further enhance the CAM photosynthetic fixation capacity (Fig. 5D).

To evaluate if the photosynthetic capacity also correlates with the following flower development, 'TS97' plants were induced to flower under various daylengths and $23 / 18{ }^{\circ} \mathrm{C}$ day/ night temperature. The daylength had no effect on time of spiking (Fig. 6A). The effects of daylength on flower development became more obvious with increasing time in treatment. The short 6- to 8-h daylengths delayed the time to flower bud formation, 5 to $6 \mathrm{~d}$ later than the 12-h daylength (Fig. 6B). Similarly, short daylengths slowed anthesis, 6 to $10 \mathrm{~d}$ later than daylengths longer than $12 \mathrm{~h}$ (Fig. 6C). Eventually, the 
Table 1. Effect of low-light exposure for $4 \mathrm{~h}$ on the values of $\mathrm{F}_{\mathrm{v}} / \mathrm{F}_{\mathrm{m}}$, initial and maximum chlorophyll fluorescence, $\mathrm{F}_{\mathrm{o}}$, and $\mathrm{F}_{\mathrm{m}}$ in Phalaenopsis amabilis 'TS97' leaves. ${ }^{\mathrm{z}}$

\begin{tabular}{|c|c|c|c|c|c|c|c|c|c|}
\hline \multirow[b]{3}{*}{ Treatment $^{\mathrm{y}}$} & & & & \multicolumn{3}{|c|}{ Malate } & \multicolumn{3}{|c|}{ Titratable acidity } \\
\hline & \multicolumn{3}{|c|}{ PSII efficiency } & Pre-dusk & Pre- daw1 & Net & Pre-dusk & Pre- dawn & Net \\
\hline & $\overline{\mathrm{F}_{\mathrm{o}}}$ & $\mathrm{F}_{\mathrm{m}}$ & $\mathrm{F}_{\mathrm{v}} / \mathrm{F}_{\mathrm{m}}$ & \multicolumn{3}{|c|}{$\left(\mathrm{mmol} \cdot \mathrm{g}^{-1} \mathrm{FW}\right)$} & \multicolumn{3}{|c|}{$\mathrm{H}^{+}\left(\mathrm{mmol} \cdot \mathrm{g}^{-1} \mathrm{FW}\right)$} \\
\hline$\overline{\mathrm{HH}}$ & $762 a^{x}$ & $3207 \mathrm{a}$ & $0.762 \mathrm{~b}$ & $2.4 \mathrm{~b}$ & $107.0 \mathrm{a}$ & $104.6 \mathrm{a}$ & $13.5 \mathrm{a}$ & $168.4 \mathrm{~b}$ & $148.9 \mathrm{~b}$ \\
\hline ML & $740 \mathrm{a}$ & $3244 \mathrm{a}$ & $0.772 \mathrm{~b}$ & $5.6 \mathrm{~b}$ & $114.3 \mathrm{a}$ & $108.8 \mathrm{a}$ & $9.1 \mathrm{a}$ & $211.3 \mathrm{a}$ & $202.1 \mathrm{a}$ \\
\hline PL & $677 \mathrm{a}$ & $3298 \mathrm{a}$ & $0.794 \mathrm{a}$ & $15.3 \mathrm{a}$ & $115.6 \mathrm{a}$ & $100.2 \mathrm{a}$ & $19.2 \mathrm{a}$ & $229.2 \mathrm{a}$ & $210.0 \mathrm{a}$ \\
\hline
\end{tabular}

${ }^{z}$ The same leaves as those in Figure 4 were measured. Levels of malate and titratable acid at pre-dusk, pre-dawn, and net nocturnal accumulation are also shown. Results are means $(\mathrm{n}=3)$.

${ }^{\mathrm{y}} \mathrm{Low}-$ light treatment $\left(30 \mathrm{mmol} \cdot \mathrm{m}^{-2} \cdot \mathrm{s}^{-1}\right)$ in the morning [AL (0700 to $\left.1100 \mathrm{HR}\right)$ ], at noon [ML (1100 to $\left.1500 \mathrm{HR}\right)$ ], and in the afternoon [PL (1500 to $1900 \mathrm{HR})]$ under a 12-h daylength; $\mathrm{HH}=$ control leaves grown under 12-h saturating light.

${ }^{x}$ Mean separation (in columns) by Duncan's multiple range test at $P<0.05$.

PSII = photosystem II; FW = fresh weight.

6- to 8-h daylength treatments resulted in fewer total flowers and buds, on average 2.5 to seven, than the 12-h daylength (Fig. 6D). The 14- to 16-h daylengths neither accelerated flower formation nor enhanced total flower count (Fig. 6A-D).

\section{Discussion}

Under various light conditions (Figs. 1A, 3A, 4A, and $5 \mathrm{~A}-\mathrm{C}$ ), temperature, and developmental age (Guo and Lee, 2006), 'TS97' leaves all exhibited the typical diurnal $\mathrm{CO}_{2}$ uptake rhythm, indicating that $P$. amabilis is an obligate CAM plant. In a fast-growing 'TS97' plant, the daily total $\mathrm{CO}_{2}$ uptake, an indicator of photosynthetic capacity, saturated at a higher $P P F$ of $\approx 200 \mu \mathrm{mol} \cdot \mathrm{m}^{-2} \cdot \mathrm{s}^{-1}$ (Fig. 1B) than a slowgrowing Phalaenopsis hybrid, $130 \mu \mathrm{mol} \cdot \mathrm{m}^{-2} \cdot \mathrm{s}^{-1} P P F$ (Ota et al., 1991). The same trend based on instant net $\mathrm{CO}_{2}$ uptake rate has been reported in a Phalaenopsis hybrid (Hou et al., 2010). A PPF above $200 \mu \mathrm{mol} \cdot \mathrm{m}^{-2} \cdot \mathrm{s}^{-1}$ promoted both daytime and nighttime $\mathrm{CO}_{2}$ uptake rates (Figs. $1 \mathrm{~A}$ and $3 \mathrm{~A}$ ) and resulted in low level of pre-dusk malate/titratable acid (Fig. 1C-D). These results are consistent with previous observations that high irradiance accelerates daytime malate decarboxylation and fixation to carbohydrate through Calvin cycle and thus enhances stomata opening in the afternoon (Phase IV) and the activity of nocturnal phosphoenolpyruvate carboxylase in CAM plants (Kluge and Ting, 1978; Lüttge, 2008). That in turn explains that the $\mathrm{CO}_{2}$ uptake rate and capacity, particularly the daytime total $\mathrm{CO}_{2}$ uptake, in 'TS97' leaves were greatly reduced under low $P P F\left(0\right.$ to $\left.90 \mu \mathrm{mol} \cdot \mathrm{m}^{-2} \cdot \mathrm{s}^{-1}\right)$ (Figs. $1 \mathrm{~A}-\mathrm{B}$ and $3 \mathrm{~A}-\mathrm{B})$. The relatively low-light requirement for activating positive carbon fixation in 'TS97' leaves (Fig. 1B-D) clearly shows the efficient use of light energy (Skillman and Winter, 1997). In general, the daytime $\mathrm{CO}_{2}$ uptake required a higher $P P F$ than the nighttime $\mathrm{CO}_{2}$ uptake to compensate for the respirational carbon loss (Figs. $1 \mathrm{~B}$ and $3 \mathrm{~B}$ ); that is probably because the $\mathrm{CO}_{2}$ fixation during Phase IV is mainly through the $\mathrm{C}_{3}$ pathway (Lüttge, 2008). Previous reports have indicated that CAM plants can achieve a productivity close to $\mathrm{C}_{3}$ or $\mathrm{C}_{4}$ by maximizing carbon gain during Phase IV (Lüttge, 2008). Taken together, saturating lighting in the afternoon may enhance photosynthetic capacity in Phalaenopsis that may partially contribute to better growth.

An increase of pre-dawn malate or titratable acidity was usually accompanied by an initial decrease of pre-dusk acid level (Fig. 1C-D), indicating that the nighttime carbon fixation ability depends on whether the previously accumulated acid is completely metabolized during the day (Lüttge, 2008). At least $90 \mu \mathrm{mol} \cdot \mathrm{m}^{-2} \cdot \mathrm{s}^{-1} P P F$ was required to completely decarboxylate the accumulated malate during the day in 'TS97' leaves (Fig. 1B); that was consistent with the distinct daytime $\mathrm{CO}_{2}$ uptake after exposure to $90 \mu \mathrm{mol} \cdot \mathrm{m}^{-2} \cdot \mathrm{s}^{-1} P P F$ (Fig. 1A). Although a high $P P F$ above $\approx 200 \mu \mathrm{mol} \cdot \mathrm{m}^{-2} \cdot \mathrm{s}^{-1}$ did not decrease the total $\mathrm{CO}_{2}$ uptake (Figs. $1 \mathrm{~B}$ and $3 \mathrm{~B}$ ), the chlorophyll fluorescence ratio, $\mathrm{F}_{\mathrm{v}} / \mathrm{F}_{\mathrm{m}}$, had been reduced to 0.68 to 0.74 when leaves were exposed to 325 to $400 \mu \mathrm{mol} \cdot \mathrm{m}^{-2} \cdot \mathrm{s}^{-1} P P F$ (Fig. 2A). The $\mathrm{F}_{\mathrm{v}} / \mathrm{F}_{\mathrm{m}}$ value represents the maximal quantum yield of PSII, usually ranging between 0.75 and 0.85 for nonstressed plants (Bolhar-Nordenkampf et al., 1989). Thus, the low $\mathrm{F}_{\mathrm{v}} / \mathrm{F}_{\mathrm{m}}$ value under a high $P P F$ suggests the possibility of PSII photoinhibition that also correlates with the damages of PSII indicated by an increase in $\mathrm{F}_{\mathrm{o}}$ values (Fig. 2B) (Maxwell and Johnson, 2000). Although a 10-min dark adaptation during our fluorescence measurements might not have been long enough to fully adapt the leaves that were exposed to a high $P P F$, the same result was also observed in a Phalaenopsis hybrid after exposure to $399 \mu \mathrm{mol} \cdot \mathrm{m}^{-2} \cdot \mathrm{s}^{-1} P P F$ (Hou et al., 2010). Similarly, the net nocturnal malate fixation also decreased in leaves after exposure to $325 \mu \mathrm{mol} \cdot \mathrm{m}^{-2} \cdot \mathrm{s}^{-1} P P F$ (Fig. $1 C)$. Although the amount of acid in leaves remained at a high level under $450 \mu \mathrm{mol} \cdot \mathrm{m}^{-2} \cdot \mathrm{s}^{-1} P P F$, the accumulated acid was probably a protection mechanism to reduce photoinhibition (Osmond, 1982; Scheibe et al., 2005). Based on all the results regarding carbon fixation capacity and PSII efficiency, the optimal PPF for the maximal photosynthesis in Phalaenopsis leaves appears to be $\approx 200 \mu \mathrm{mol} \cdot \mathrm{m}^{-2} \cdot \mathrm{s}^{-1} P P F$.

When the 'TS97' leaves developed under low light (LLA), the daily total $\mathrm{CO}_{2}$ uptake saturated at a low PPF, 125 $\mu \mathrm{mol} \cdot \mathrm{m}^{-2} \cdot \mathrm{s}^{-1}$. The same trend is also observed in LLA leaves of tropical CAM plants (Adams and Osmond, 1988). Our results also imply an enhanced sensitivity of LLA leaves to high-light photoinhibition in 'TS97' plants as observed in shade-adapted tropical CAM plants (Adams and Osmond, 1988). That also correlates with the observation that PSII photoinhibition occurs when Phalaenopsis leaves are directly exposed to $200 \mu \mathrm{mol} \cdot \mathrm{m}^{-2} \cdot \mathrm{s}^{-1} P P F$ without acclimation after an extended time in darkness (Hou et al., 2010). Nevertheless, the maximum daily total $\mathrm{CO}_{2}$ in a LLA leaf was only slightly lower than the normal leaf that developed under saturating irradiance (Figs. 1B and 3B), demonstrating great flexibility of carbon fixation to low-light acclimation in 'TS97' leaves. That is 

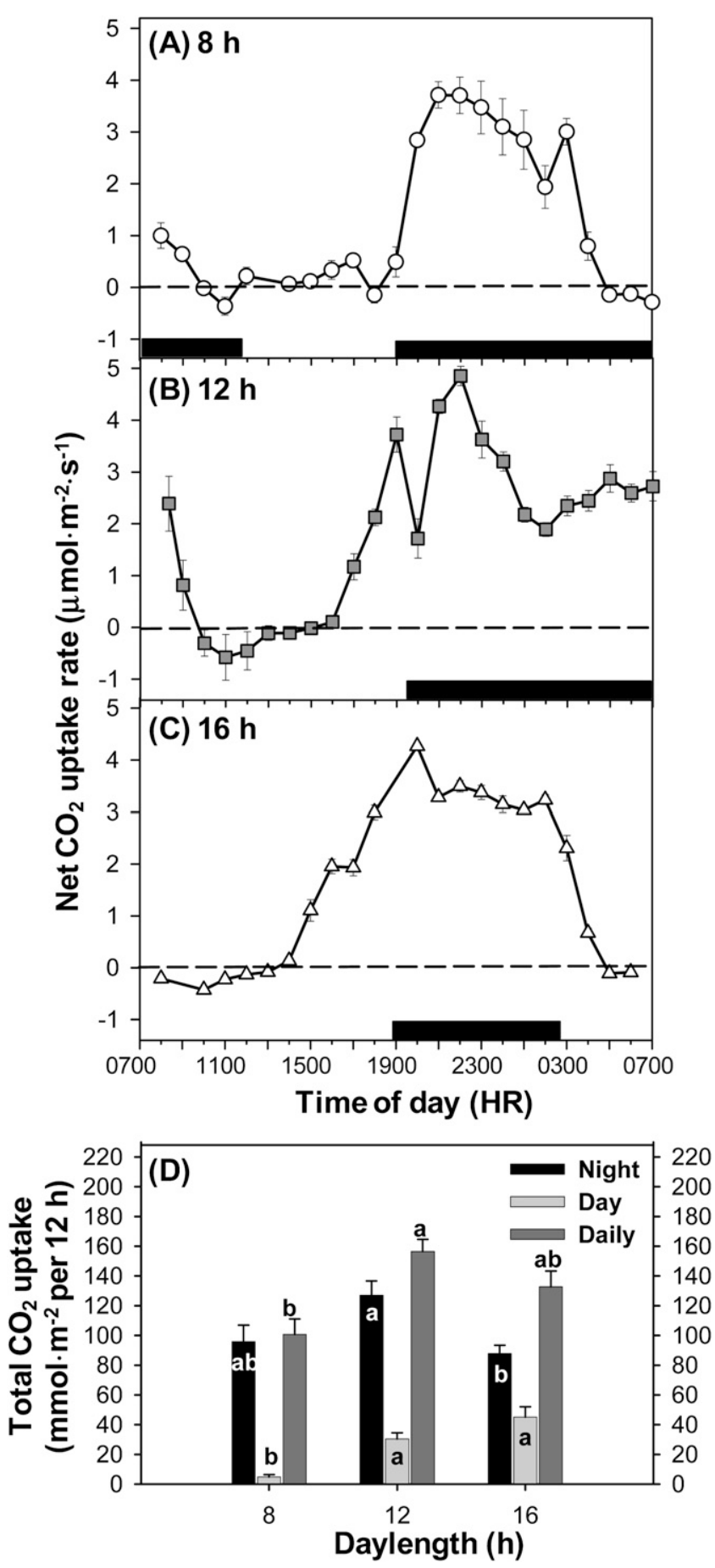

Fig. 5. Effects of (A) 8-h, (B) 12-h, or (C) 16-h daylength on diurnal changes of net $\mathrm{CO}_{2}$ uptake rate and (D) total $\mathrm{CO}_{2}$ uptake during the night (black), during the day (gray), and over a daily 24-h period (dark gray) in Phalaenopsis amabilis 'TS97' leaves. Results are means $\pm \mathrm{SE}(\mathrm{n}=3)$; $(\square)$ : darkness. Means with the same letter are not significantly different at $P<0.05$ by Duncan's multiple range test.

consistent with the tolerance of PSII photochemical efficiency and leaf growth to long-term darkness observed in 'TS97' plants (Lin and Hsu, 2004) and another CAM species (Skillman and Winter, 1997). In addition, our results suggest that the photosynthetic capacity in mature 'TS97' leaves is mainly regulated by current light environments and less by the developmental factors such as plant age and leaf position, as observed previously (Guo and Lee,
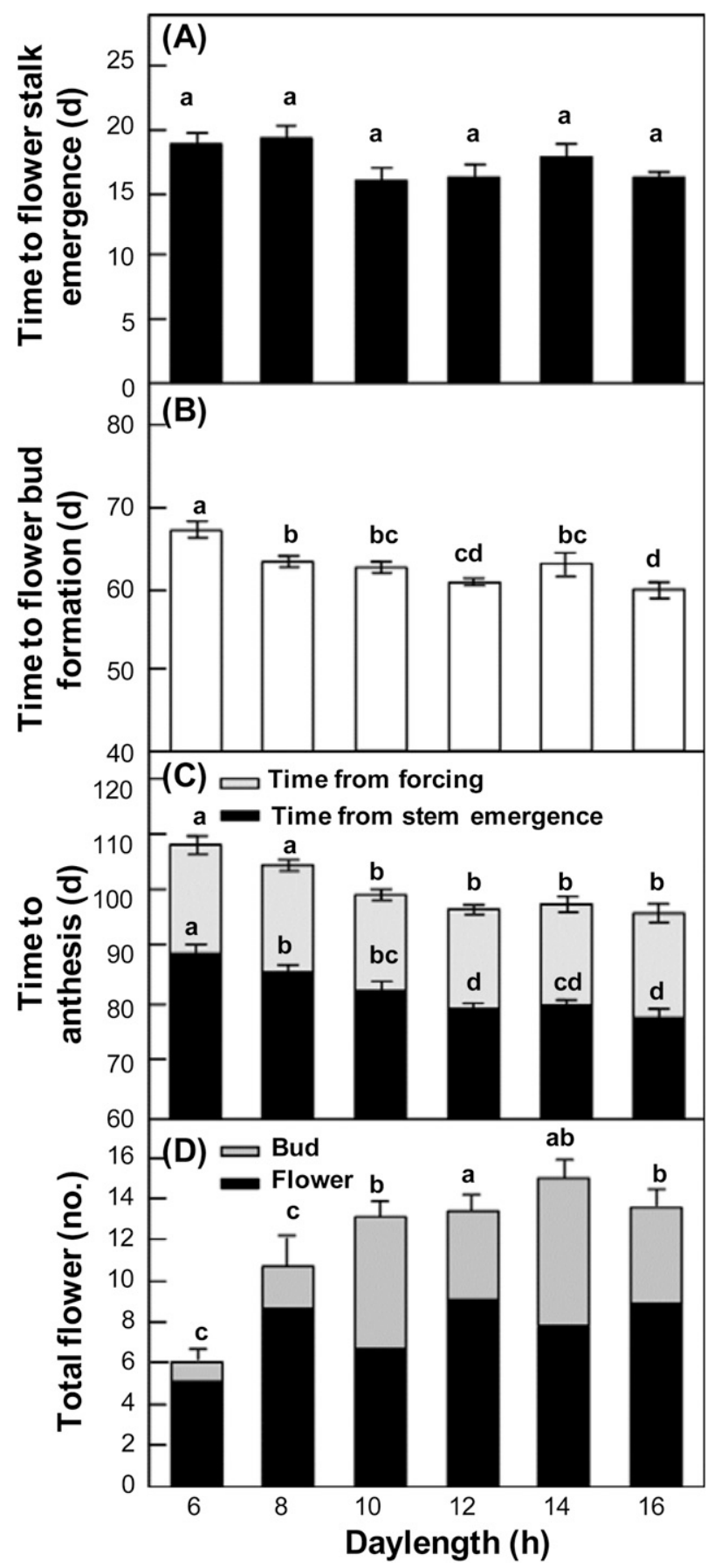

Fig. 6. Effect of daylength on flower development in Phalaenopsis amabilis 'TS97': (A) time to flower stalk emergence, (B) time to flower bud formation, (C) time to anthesis, and (D) total flower count were shown when plants grown under 6-, 8-, 10-, 12-, 14-, and 16-h daylengths along with $23 / 18{ }^{\circ} \mathrm{C}$ day/night temperature for flower induction. Results are means $\pm \operatorname{SE}(n=10)$. Means with the same letter are not significantly different at $P<0.05$ by Duncan's multiple range test. The significant differences between total flower count (bud + flower) are shown (D).

2006). That also correlates with studies that, despite low-light stress during the vegetative stage, saturating irradiance supplemented during the reproductive stage is sufficient for high-quality flower formation in 'TS97' plants (Lin, 1994).

In addition, a $4 \mathrm{~h}$ of LLE at any time during the day under a 12-h daylength with $8 \mathrm{~h}$ of $200 \mu \mathrm{mol} \cdot \mathrm{m}^{-2} \cdot \mathrm{s}^{-1} P P F$ did not affect 
total $\mathrm{CO}_{2}$ uptake, PSII efficiency, or nocturnal malate fixation (Fig. 4; Table 1), indicating that $8 \mathrm{~h}$ of a saturating $P P F$ at 200 $\mu \mathrm{mol} \cdot \mathrm{m}^{-2} \cdot \mathrm{s}^{-1}$ is sufficient to decarboxylate the accumulated malate to promote nocturnal carbon fixation in 'TS97' leaves. In CAM species, a short daylength would result in incomplete decarboxylation of the accumulated malate that inhibits stomata opening in Phase IV and thus lowers the nighttime $\mathrm{CO}_{2}$ fixation (Lüttge, 2008). The same results were observed in 'TS97' leaves in which the 8-h daylength nearly diminished the daytime $\mathrm{CO}_{2}$ uptake and caused a lower nocturnal $\mathrm{CO}_{2}$ uptake rate compared with those under the 12-h daylength (Fig. 5A-B). Although the 16-h daylength did not affect daytime $\mathrm{CO}_{2}$ uptake in 'TS97' leaves, it resulted in $5 \mathrm{~h}$ fewer of $\mathrm{CO}_{2}$ absorption and $25 \%$ less nocturnal total $\mathrm{CO}_{2}$ uptake than the 12-h daylength (Fig. 5). The trends of photosynthetic capacity as a result of various daylengths were consistent with later flowering performance (Fig. 6). In general, the 12-h daylength resulted in earlier flower development and higher flower count than 6- to 8-h daylengths. The results from this work are in conflict with a previous report that a short daylength of $8 \mathrm{~h}$ could promote flower formation and total flower count in a Phalaenopsis hybrid (Yoneda et al., 1991). It is possible that $P$. amabilis orchid is originated from the region close to latitude $23^{\circ} \mathrm{N}$, where there is little daylength change during the year. Similarly, longer daylength than $12 \mathrm{~h}$ did not enhance flowering performance, indicating that artificial lighting of $12 \mathrm{~h}$ during flower-forcing in the field would be sufficient for maximizing flower production.

In conclusion, the light requirement of maximal photosynthetic ability in $P$. amabilis 'TS97' leaves is $\approx 200 \mu \mathrm{mol} \cdot \mathrm{m}^{-2} \cdot \mathrm{s}^{-1} P P F$ and $125 \mu \mathrm{mol} \cdot \mathrm{m}^{-2} \cdot \mathrm{s}^{-1} P P F$ for low-light-adapted leaves. A daylength of $12 \mathrm{~h}$ maximizes the photosynthetic $\mathrm{CO}_{2}$ fixation and flower development. To reduce the cost of artificial lighting, $8 \mathrm{~h}$ of saturating $P P F$ that is followed by $4 \mathrm{~h}$ of low light is sufficient for optimal photosynthesis. A constant high $P P F$ above $320 \mu \mathrm{mol} \cdot \mathrm{m}^{-2} \cdot \mathrm{s}^{-1}$ under a 12 -h daylength would cause photoinhibition and result in reduced $\mathrm{CO}_{2}$ fixation in Phalaenopsis leaves.

\section{Literature Cited}

Adams, W.W. and C.B. Osmond. 1988. Internal $\mathrm{CO}_{2}$ supply during photosynthesis of sun and shade grown CAM plants in relation to photoinhibition. Plant Physiol. 86:117-123.

Bolhar-Nordenkampf, H.R., S.P. Long, N.R. Baker, G. Oquist, U. Schreiber, and E.G. Lechner. 1989. Chlorophyll fluorescence as a probe of the photosynthetic competence of leaves in the field: A review of current instrumentation. Funct. Ecol. 3:497-514.

Brulfert, J., D. Müller, M. Kluge, and O. Queiroz. 1982. Photoperiodism and crassulacean acid metabolism. Planta 154:326-331.

Chen, W.H. and Y.T. Wang. 1996. Phalaenopsis orchid culture. Taiwan Sugar 43:6-11.

Christenson, E.A. 2001. Phalaenopsis: A monograph. Timber Press, Portland, OR.

Cushman, J.C. and H.J. Bohnert. 1999. Crassulacean acid metabolism: Molecular genetics. Annu. Rev. Plant Physiol. Plant Mol. Biol. 50:305-332.

Endo, M. and I. Ikusima. 1989. Diurnal rhythm and characteristics of photosynthesis and respiration in the leaf and root of a Phalaenopsis plant. Plant Cell Physiol. 30:43-47.

Guo, W.J. and N. Lee. 2006. Effect of leaf and plant age, and day/night temperature on net $\mathrm{CO}_{2}$ uptake in Phalaenopsis amabilis var. formosa. J. Amer. Soc. Hort. Sci. 131:320-326.

Hou, J.Y., W.B. Miller, and Y.C.A. Chang. 2011. Effects of simulated dark shipping on the carbohydrate status and postshipping performance of Phalaenopsis. J. Amer. Soc. Hort. Sci. 136:364-371.
Hou, J.Y., T.L. Setter, and Y.C.A. Chang. 2010. Effects of simulated dark shipping on photosynthetic status and post-shipping performance in Phalaenopsis Sogo Yukidian 'V3'. J. Amer. Soc. Hort. Sci. 135:183-190.

Johnson, C.M., P.R. Stout, T.C. Broyer, and A.B. Carlton. 1957. Comparative chlorine requirements of different plant species. Plant Soil 8:337-353.

Kluge, M. and I.P. Ting. 1978. Crassulacean acid metabolism. Analysis of an ecological adaptation. Springer-Verlag, New York, NY.

Konow, E.A. and Y.T. Wang. 2001. Irradiance levels affect in vitro and greenhouse growth, flowering, and photosynthetic behavior of a hybrid Phalaenopsis orchid. J. Amer. Soc. Hort. Sci. 126:531-536.

Lee, N. 2000. Phalaenopsis orchid light requirements. HortTechnology 10:430.

Lin, G.M. and N. Lee. 1988. Leaf area estimation and the effect of temperature on the growth of Phalaenopsis leaves. J. Chinese Soc. Hort. Sci. 34:73-80.

Lin, M.J. and B.D. Hsu. 2004. Photosynthetic plasticity of Phalaenopsis in response to different light environments. J. Plant Physiol. 161:1259-1268.

Lin, Y.Z. 1994. Effect of light, temperature and plant growth regulators on growth and flowering of Phalaenopsis sp. Master's diss., Dept. Hort. Landscape Architecture, National Taiwan Univ., Taipei, Taiwan.

Lin, Y.Z. and N. Lee. 1998. Light requirement of Phalaenopsis during prior to and following cool-temperature forcing. J. Chinese Soc. Hort. Sci. 44:463-478.

Lootens, P. and J. Heursel. 1998. Irradiance, temperature, and carbon dioxide enrichment affect photosynthesis in Phalaenopsis hybrids. HortScience 33:1183-1185.

Lüttge, U. 2008. Crassulacean acid metabolism. Wiley, Hoboken, NJ. Maxwell, K. and G.N. Johnson. 2000. Chlorophyll fluorescence-A practical guide. J. Expt. Bot. 51:659-668.

Nobel, P.S. 1991. Achievable productivities of certain CAM plants: Basis for high values compared with $\mathrm{C}_{3}$ and $\mathrm{C}_{4}$ plants. New Phytol. 119:183-205.

Nose, A., K. Heima, K. Miyazato, and S. Murayama. 1986. Effects of daylength on CAM type $\mathrm{CO}_{2}$ and water vapour exchange of pineapple plants. Photosynthetica 20:20-28.

Osmond, C.B. 1982. Carbon cycling and stability of the photosynthetic apparatus in CAM, p. 112-127. In: Ting, I.P. and M. Gibbs (eds.). Crassulacean acid metabolism. Amer. Soc. Plant Physiol., Rockville, MD.

Osmond, C.B., W.W.A. III., and S.D. Smith. 1991. Crassulacean acid metabolism, p. 255-280. In: Pearcy, R.W., J. Ehleringer, H.A. Mooney, and P.W. Rundel (eds.). Plant physiological ecology: Field methods and instrumentation. Springer-Verlag, New York, NY.

Ota, K., K. Morioka, and Y. Yamamoto. 1991. Effects of leaf age, inflorescence, temperature, light intensity and moisture conditions on CAM photosynthesis in Phalaenopsis. J. Jpn. Soc. Hort. Sci. 60:125-132.

Queiroz, O. 1974. Circadian rhythms and metabolic patterns. Annu. Rev. Plant Physiol. Plant Mol. Biol. 25:115-134.

Scheibe, R., J.E. Backhausen, V. Emmerlich, and S. Holtgrefe. 2005. Strategies to maintain redox homeostasis during photosynthesis under changing conditions. J. Expt. Bot. 56:1481-1489.

Sekizuka, F., A. Nose, Y. Kawamitsu, S. Murayama, and K. Arisumi. 1995. Effects of day length on gas exchange characteristics in Crassulacean acid metabolism plant, Dendrobium ekapol cv. Panda Jpn. J. Crop Sci. 64:201-208.

Skillman, J.B. and K. Winter. 1997. High photosynthetic capacity in a shade-tolerant crassulacean acid metabolism plant (implications for sunfleck use, nonphotochemical energy dissipation, and susceptibility to photoinhibition). Plant Physiol. 113:441-450.

U.S. Department of Agriculture. 2012. Floriculture crops summary 2011. U.S. Dept. Agr., Washington, DC.

Wang, Y.T. 1995. Phalaenopsis orchid light requirement during the induction of spiking. HortScience 30:59-61.

Yoneda, K., H. Momose, and S. Kubota. 1991. Effects of daylength and temperature on flowering in juvenile and adult Phalaenopsis plants. J. Jpn. Soc. Hort. Sci. 60:651-657. 